\title{
Phenomenon of Interaction between Organizational Climate and Human Resource Assessment in Large Public Sector Organisations
}

\author{
PALMIRA PAPSIENE ${ }^{1}$, DAINORA VAITKEVICIENE ${ }^{2}$, INGA VIDREVICIENE ${ }^{3}$ \\ ${ }^{1}$ Faculty of Bioeconomy Development, VYTAUTAS MAGNUS UNIVERSITY AGRICULTURE ACADEMY, LITHUANIA. \\ E-mail: palmira.papsiene@gmail.com \\ ${ }^{2}$ Faculty of Business, Department of Accounting and Finance, KAUNAS UNIVERSITY OF APPLIED SCIENCES, \\ LITHUANIA. E-mail: dainora.vaitkeviciene@gmail.com \\ ${ }^{3}$ Faculty of Bioeconomy Development, VYTAUTAS MAGNUS UNIVERSITY AGRICULTURE ACADEMY, LITHUANIA. \\ E-mail: inga.vidreviciene@gmail.com
}

\begin{abstract}
While intensively researching organizational climate and human resource assessment, the question naturally arises, in case these both phenomena operate in the same organization, what is a relationship between them? This question is answered by a survey in which human resource assessment was represented by fifty questions combined into three latent variables: assessment methodology, assessment organization, decisions and implementation, and organizational climate was represented by thirty-nine questions combined into a common latent variable of organizational climate. By comparing latent variables of human resource assessment and organizational climate the cluster model of the interaction between human resource assessment and organizational climate was formed. A total of four types have been identified, three of which are more favourable to the implementation stage of human resource assessment than organisational climate, and one where the organisational climate is indifferent in the context of human resource assessment. This research collected information on phenomenon of human resource assessment impact on organizational climate in large organizations, as it is more pronounced there. Also, human resource assessment process is more full and more formalized in these organizations, and organizational climate is the result of interaction between the individuals in the group and not the impact by a single individual.
\end{abstract}

Keywords: Human Resource Assessment, Organizational Climate, Interaction Types, Phenomenon, Model

JEL Classification: O15, M12

Recibido: 7 de Diciembre de 2020

Aceptado: 2 de Febrero de 2021 


\section{Introduction}

The topics of human resource assessment and organizational climate have been intensively studied in scientific literature to date (Weer, \& Greenhaus, 2020; Nasreen et al. 2019; Moyle, \& Hackston, 2018; Bolinger et al. 2018; El-Majali, 2016; Ahmadi, 2012; Buys, \& Louw, 2012; Purohit, \& Wadhawa 2012; Mathur, \& Nihalani, 2011; Goyal, 2010; Srivastav, 2009). Meanwhile, the interaction between human resource assessment and the organisation's climate has been little studied in the literature, and wherever it is mentioned, it is revealed as a co-effect of one of them: human resource assessment or organisation's climate assessment.

The interaction between variables of human resource assessment and organisational climate in the authors' work reveals itself when the authors analyse a relationship between elements of organisation's climate and the organisation's performance indicators when the latter gets the part of human resource indicators (Patterson et al. 2004); or through analysis of the phenomenon of work characteristics and psychosocial stress expression, which also includes some part of organizational climate and human resource assessment indicators (Dickson et al. 2006).

The science of management still lacks in depth studies that help to know the phenotype of human resource assessment in the context of organisational climate. Therefore, the practices are rarely noticed in organizations when human resource assessment impact on organizational climate is being monitored and controlled. In many cases, human resource assessment in organizations is identified as a process that ensures quality and sustainability of human resources, and changes in organisational climate that result from it are often either not observed at all or accepted as an inevitable outcome of the assessment with which a common organisation is inclined to accept (Gökalp et al., 2020; Vrchota, \& Řehoř, 2019; Stan, 2018; Khan \& Qureshi, 2020). However, from an organizational perspective, it can be stated that existence of two different objects, i.e. human resource assessment and organizational climate, in the same space, i.e. in the organization, at the same time makes a hypothetical statement about the existence of their interaction as well and believe that knowledge of this interaction in the future will allow to manage the impact of human resource evaluation on organizational climate.

While modelling the impact of human resource assessment on organisation's climate, theoretical definitions of human resource assessment and organisation climate are chosen that identify individual identity of both constructs and allow to identify the essential criteria for human resource assessment and organisation's climate interaction that enable the formation of criteria of interaction of human resource assessment and organisational climate. The analysis of definitions of human resource assessment and organizational climate has shown that theoretically, within an organization, types of interaction between different human resource assessment practices and organizational climate characteristics can form, by which a specific relationship can be identified.

The research goal is to establish a typological model of interaction between human resource assessment and organizational climate.

Research methods: data collected by using a questionnaire of opinions - preferences; factor and reliability analysis methods used for verification of latent variables; $\mathrm{k}$-mean cluster method used to determine types of human resource assessment and organizational climate. The research was performed in large public sector organizations.

\section{Literature Review}

In scientific literature the impact of human resource assessment (HRA) on organizational climate $(\mathrm{OC})$ is still less acknowledged. Mostly, these are random insights of authors, that have emerged as an indirect result of separate studies of either HRA, or OC (Gökalp et al. 2020; Wang et al. 2019; Gelbard et al. 2018; Milutinovic, \& Kerkez, 2017; Brutu, \& Mihai, 2017; Tan, \& Nasurdin, 2011; Ansoff, 1989; Patterson et al. 2004; Rekasiute-Balsiene 2005; Dickson et al. 2006; Kundu, 2007; Holloway, 2012; Protasova, 2010. Schneider, \& Barbera, 2014; Bolinger et al. 2018; Asio, \& Jimenez, 2020). It should be noted that the direct interaction between human resource assessment and organization's climate in 
the reviewed works of the authors has not been examined. From the perspective of this research, the emergence of such findings can be treated as an argument that influence between the above constructs exists, just a complex cognition of this influence as a peculiar phenomenon is required (Papsiene, \& Vaitkevicius, 2013; 2014). An important argument for the problem they are studying is that the interaction between human resource assessment and organisational climate can also explain the result of human resource management.

As fundamental basis for the ongoing research of the mutual influence of human resource assessment and organisational climate variables is not complete in integrated viewpoint in other authors' sources, the definitions / attributes of human resource assessment and organisational climate are chosen as the basis for this research to better describe the impact of human resource assessment on organisational climate. Namely from the identity of human resource assessment and organizational climate the areas of their possible mutual influence and the directions of their potential influence have been distinguished.

Analysed literature on human resource assessment and organizational climate suggests that organizational climate depends on the employee's involvement into designing of the assessment system, the type of feedback prevailing in the organization, and the prevailing promotion system (Dransfield, 2000). In addition, the constant assessment affects the assessment of organization's climate friendliness. As one of the positive features of the assessment is the fact that during the assessment the employee becomes familiar with his or her strengths and weaknesses, which allows for strategic planning of qualification development and training, which often corresponds the employee's expectations (Ansoff, 1989).

In addition, R. Dransfield (2000) noted that organizational climate depends on the employee's involvement in the designing of the assessment system, the predominance of the type of feedback in the organization, the prevailing system of promotion. The named elements can be attributed to human resource assessment, since, firstly, they describe human relations and, secondly, they define the outline of the assessment system. Another important insight is the reactivity of management to postevaluation changes and their control (Ansoff, 1989), which allows to link human resource assessment described in Ansoff's approach ("management reactivity " and " change ... control"), and organizational climate, which is defined by a percept of organizational climate that formed as a result of "management reactivity" and "change ... control".

When discussing the content of human resource assessment, the literature distinguishes: knowledge of assessment objectives, creation of assessment system, assessment methodology (AM), selection of assessors, etc. (Thom, \& Ritz, 2004). Here it is worth noting that the authors analyse human resource assessment in the context of motivation, which can be associated with organizational climate (Kets de Vries et al. 2006). This is because organization's climate is formed through the social behaviour of individuals, which is modified and shaped by the motivational system (Neal et al. 2005). R. Rekasiute-Balsiene (2005) gives an insight, where she notes that organizational climate creates an atmosphere of interpersonal functioning of employees in the workplace. Thus, often the influence between human resource assessment and organisation's climate is evident in the fundamentals of human resource assessment and organisation's climate concepts and their coherence.

While describing the impact of human resource assessment on organisation's climate, another important element of human resource assessment is the assessment organisation (VO), which indicates the effectiveness of personnel evaluation (Grote, 2002; Yee et al. 2009). Here, as in previous cases, "the effectiveness of personnel evaluation" implicit describes the factor of organization's climate formation, which can link human resource assessment with organization's climate.

In the construct of human resource assessment there were distinguished decisions and their implementation (SI), which make sense if (SI) does not lead to negative consequences for the employee and the employee is satisfied with the assessment results (Anwar et al. 2016). The latter characteristic of human resource assessment was distinguished in order to model the relationship between the 
assessment organisation and the assessment discussion with organizational climate, because the literature reviewed failed to find a description of their impact on organizational climate.

The insights of authors reviewed during psychological and managerial literature analysis (Patterson et al. 2004; Rekasiute-Balsiene, 2005; Dickson et al. 2006; Kundu, 2007; Holloway, 2012) have made it possible to construct a theoretical model of interaction between the organization's climate features based on the following factors: security and definiteness (SD), diligence and creativity (DC), values and traditions (VT), relationships and communication (RC), attractiveness of the work process (WP) and conflicts (C).

Discussed human resource assessment and organizational climate enabled rethinking of possible logical interactions between human resource assessment and organizational climate features.

\section{Methodology}

Methodology of verification of organizational climate and human resource assessment. Empirical interaction between HRA (human resources assessment) and OC (organizational climate) has been verified by using a questionnaire methodology. The research was explorative, therefore there was carried out an additional verification of OC and HRA variables by applying methods of factor and reliability analysis. In striving for higher reliability of results, during their application there were assessed latent variables' assessment methodology (AM), solutions and implementation (SI), organization of assessment $(\mathrm{OA})$ and organization climate $(\mathrm{OC})$ inter-item relatedness and their empirical quality.

Figure. 1 Results of factor and reliability analysis of the organisational climate and human resource assessment indices

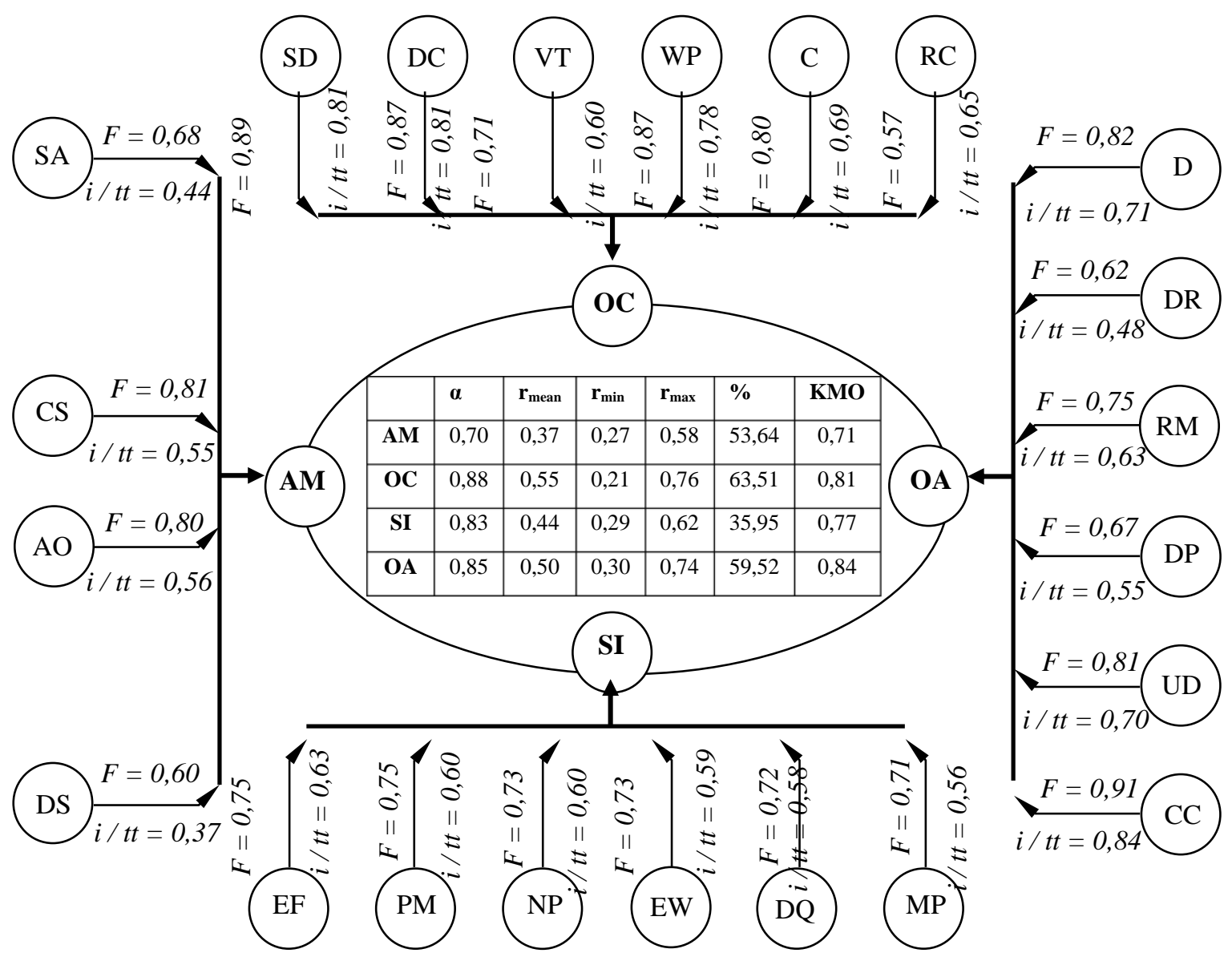


Table 1. Results of factor and reliability analysis of HRA and OC indices

\begin{tabular}{|c|c|c|c|c|c|c|c|c|}
\hline & $\boldsymbol{\alpha}$ & $\mathbf{r}_{\text {mean }}$ & $\mathbf{r}_{\text {min }}$ & $\mathbf{r}_{\max }$ & $\%$ & KMO & Factor score & $\mathbf{i} /$ tt score \\
\hline AM & 0,70 & 0,37 & 0,27 & 0,58 & 53,64 & 0,71 & $0,81-0,60$ & $0,56-0,37$ \\
\hline SI & 0,83 & 0,44 & 0,29 & 0,62 & 35,95 & 0,77 & $0,75-0,71$ & $0,63-0,56$ \\
\hline OA & 0,85 & 0,50 & 0,30 & 0,74 & 59,52 & 0,84 & $0,91-0,62$ & $0,84-0,48$ \\
\hline OC & 0,88 & 0,55 & 0,21 & 0,76 & 63,51 & 0,81 & $0,89-0,57$ & $0,81-0,60$ \\
\hline
\end{tabular}

The questionnaire consisted of 96 closed type statements, including 7 demographic and 89 attitude and notion questions. Data analysis was carried out by using descriptive and multidimensional statistical as well classification methods. Statistical data were processed with SPSS and MS Excel. A total of 507 questionnaires returned from staff representing different organisations and positions and were assessed as suitable for analysis.

Content validity was assessed by factor analysis using a method of Principal component and adjusting factor rotation according to the highest variation method: Varimax. Finally, there were constructed additive indexes: $\mathrm{AM}, \mathrm{OA}, \mathrm{SI}$, and $\mathrm{OC}$.

All factors and indices obtained from factor and reliability analyses are statistically significant. During analysis there were obtained high Factor Scores, a sufficiently high Variance explained and hight Cronbach- $\alpha$ coefficients (see Fig.1 and Table 1). For the purpose of illustrating methodological quality, this publication presents the results of the constructive validity of the additive indices used for typological modelling.

The scale of assessment methodology (AM) is constructed from four latent variables: (DS - data sources; AO - determination of assessment objectives; CS - creation of assessment system, SA selection of assessment method). The integration of all four latent variables into the scale is characterized by high psychometric characteristics (see Fig. 1 and Table 1). The obvious difference between $L$ and $1 / t$ t indicates that the information coverage of the factor is quite large. It should be noted here that when constructing a factor depending on its purpose, combinations of psychometric properties may vary. While performing the research the provision has been followed that characteristics applied to confirmation analysis such as all high indices of factor analysis and all high indices of reliability analysis at the same time are not necessary, because we were interested not in accuracy of measurement of particular characteristics but in hypothetical compatibility of their contents. Thus, at the scale level, a greater gap between the correlative estimates by $\mathrm{L}$ and $\mathrm{I} / \mathrm{tt}$ indicates that the factor consolidates a greater diversity of contents, which allows for a wider knowledge of the phenomenon under research.

Latent variable of solutions and implementation (SI) consists of six primal variables: after assessment management of process of subdivision or organization is being developed (PM); after assessment a development of qualification and competency takes place (DQ); after assessment employees wage is being corrected (EW); after assessment new positions are given (NP); after assessment employee is being applied personal means of motivation (MP); employee's official functions are being corrected after assessment (EF), factorization results presented in Figure 1 and Table 1

While constructing the index of organization assessment, nineteen primary items are factorized into six latent variables. Factors obtained: data collection (D), DR (data control and reliability (DR), research methodology) (RM), data presentation (DP), use of data (UD), clearness and comparability of data (CC). All factors are statistically significant (see Fig.1 and Table 1).

Additive index of organizational climate $(O C)$ is constructed of latent variables: SD (security / definition), DC (diligence and creativity, VT (values and traditions), WP (attractiveness of work process), C (conflicts), RC (relationships and communication). These factors consist of 39 primary items. 
Conducted factor analysis of organizational climate is characterized by a rather high internal consistency of responses. This is indicated by the value of the Cronbach-alpha factor of 0,88 . Estimates of six factors of organizational climate: (SD - security / definition, DC - diligence and creativity, VT values and traditions, W P- attractiveness of work process, C - conflicts, RC - relationships and communication) were factorized, the obtained factors explain 63,51 percent of dispersion of all variables. It should be noted that the factors are statistically significant, which is indicated by their factor scores (see Fig. 1 and Table 1).

Verification proved that developed $\mathrm{AM}, \mathrm{OA}, \mathrm{SI}$ and $\mathrm{OC}$ is an inter-relationship assessment instrument with reliability high internal consistency and good content validity).

The assessment of classification capacity of human resource assessment and organisation's climate interaction research instrument by the $k$-mean method. $\mathrm{K}$-mean cluster analysis is chosen because of its classificational nature. A cluster analysis assessed the appropriateness of the questionnaire to classify the phenomenon according to the phenomenal characteristics of its expression in different groups of the researched population.

$\mathrm{K}$-mean cluster was applied to the $z$-standardised values of the variables, since it allowed not only to determine the number of groups, but also to assess the statistical significance of the distance between cluster centres. In this way, not only the classification potential is assessed, but also the statistical validity of the resolution.

The $Z$ scale was special because the average of the variable in it is equal to zero, and the standard deviation is equal to one. It is this condition that makes it possible to formulate a conclusion on the statistical validity of the calculated typology. This publication complied with the general requirements for the diversification of variables. In statistical theory, a standard deviation greater than one is treated as a statistically significant difference, so it can reasonably be argued that its presence between the two cluster centres indicates that the test instrument at the selected sample size has a statistically significant resolution as well.

\section{Results and Findings}

The typological model of interaction between human resource assessment and organizational climate in large public sector organizations. Having assessed distribution of features/variables according to the clusters, there were shown up four groups or respondents, which make four clusters. Three of them are similar in their assessment content; however, they differ in a degree of assessment positivity. These are the first, second, third and fourth groups of the researched (see Fig. 2).

Figure 2. Typology of organizational climate and human resource assessment process

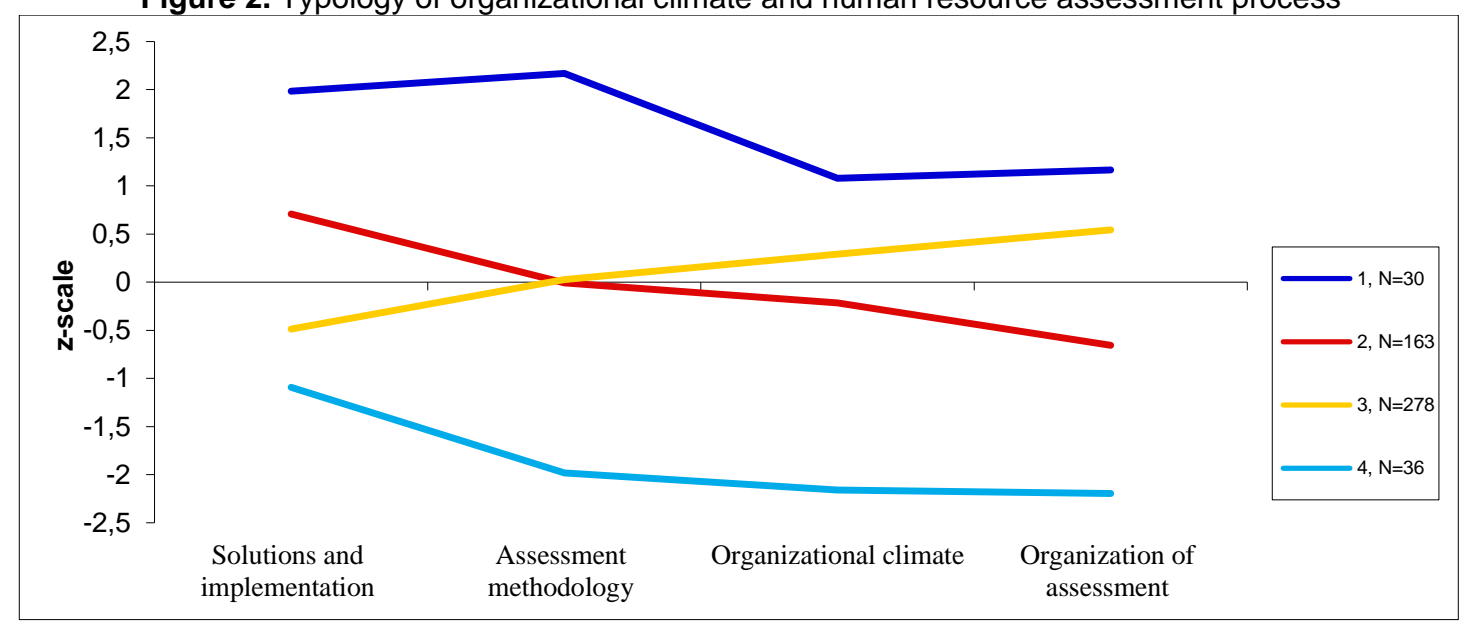

From the three named groups, the most positive assessment of human resource management and organizational climate is by the respondents of the first cluster, and the most negative - by the respondents of the fourth cluster. These groups are similar by their attitudes that are related with 
equal evaluation of assessment discussion, assessment methodology, organizational climate and assessment organization. Here should be noted that despite there is seen a difference between assessment discussion and assessment organization in the picture, however, given a standard deviation is less than one, this difference is assessed as trivial.

The first group $(\mathrm{N}=30)$ is characterized by the fact that 30 of the assessing respondents responded about the assessment discussion, assessment methodology, organizational climate and assessment organization especially positively, and emphatically stated that it is. In the first group between assessment methodology $(S D=1,983)$ and organizational climate $(S D=1,079)$ there is a difference more than one SD. That shows that assessment methodology has better assessment than organizational climate.

The second group ( $\mathrm{N}=163$ ) could be characterized as the respondents who assess assessment discussion, are indifferent to assessment methodology and unfavourably assess organizational climate and assessment organization.

The cluster of the third group $(\mathrm{N}=278)$ is interesting because opinion of the respondents prescribed to it differs from opinion of the other three clusters' respondents substantially. This difference is described by the fact that these respondents more favourably assess assessment organization than assessment discussion. Besides, the respondents of this cluster are characterized by tendency towards more favourable assessment of organizational climate as well.

The fourth group $(\mathrm{N}=36)$ of the respondents both human resource assessment and organizational climate unfavourably assesses. Since this is a small part of the respondents, therefore, having added these two facts, it could be assumed that these are the respondents who are in conflict with the organization currently.

Summarizing it could be stated that created clusters highlighted not only the assessment content, but also distinguished by the positivity between each other. Therefore, obtained representative clusterization once again proves that selected research sample is sufficient for further research of information acceptance barrier function.

\section{Conclusion}

Having carried out typological modelling of opinions of organizations' employees by using k-mean cluster method according to characteristics of human resource assessment and organizational climate, four groups of employees that form clusters showed up. Three of them are similar in content but differ among themselves in the positivity of the assessment. Those are the first, second and fourth groups of subjects under research. The third differs from them in the content of the assessment. There were formed following typological groups of employees: first group $(\mathrm{N}=30)$ is characterized by the fact that employees especially positively responded about the assessment discussion, assessment methodology, organizational climate and assessment organization and categorically stated that it is so; the second group ( $\mathrm{N}=163$ ) can be characterized as employees positively assessing the assessment discussion, indifferent to assessment methodology and negatively assessing organizational climate and assessment organization; the cluster of the third group $(\mathrm{N}=278)$ distinguishes by the fact that opinions of its employees substantially differ from those of employees of other three clusters. This difference is characterised by the fact that these respondents are assessing the assessment organisation more favourably than the discussion of the assessment. In addition, the respondents in this cluster are also prone to a more favourable assessment of the organisation's climate; the fourth group ( $N=36$ ) has an unfavourable assessment of human resources and the organisation's climate.

\section{Referencias}

1. Ahmadi, S. A. A. (2012). Performance evaluation of Tehran province payame noor university staffs (Open University) by AHP technique. Interdisciplinary Journal of Contemporary Research in Business 4 (1), 225-234. 
2. Ansoff, I. (1989). Стратегическое управление. Москва: Экономика.

3. Anwar, S., Nadeem, A. B., \& Hassan, M. (2016). Critical assessment of the impact of HR strategies on employees' performance. Journal Cogent Business \& Management, 3 (1), 1-13. http://dx.doi.org/10.1080/23311975.2016.1245939

4. Asio, J. M. R., \& Jimenez, E. C. (2020). Professional development, organizational climate, supervisory rapport and overall satisfaction of employees: An attitudinal study. International Journal of Scientific Research in Multidisciplinary Studies, 6 (4), 34-40.

5. Bolinger, A. R., Klotz, A. C., \& Leavitt, K. (2018). Contributing from inside the outer circle: The identity-based effects of noncore role incumbents on relational coordination and organizational climate. Academy of Management Review, 43 (4), 680-703. https://doi.org/10.5465/amr.2016.0333

6. Brutu, M., \& Mihai, D. (2017). The annual employee assessment versus their remuneration - a relationship meant to increase business competitiveness. Scientific Bulletin - Economic Sciences 16 (3), 80-89.

7. Buys, J., \& Louw, J. (2012). A process evaluation of a supervisory development programme. South African Journal of Human Resource Management 10 (3), 1-13. https://doi.org/10.4102/sajhrm.v10i3.423

8. Dickson, M. W., Resick, C. J., \& Hanges, P. J. (2006). When organizational climate is unambiguous, it is also strong. Journal of Applied Psychology 91 (2), 351-364. https://doi.org/10.1037/00219010.91.2.351

9. Dransfield, R. (2000). Human Resources Management (Studies in Economics \& Business). Boston: Heinemann.

10.El-Majali, B. A. W. (2016). Organizational culture and its relationship with the organizational climate in the youth higher council from the perspective of council staff. Journal of Education and Practice 7 (8), 39-51.

11.Gelbard, R., Ramon-Gonen, R., Carmeli, A., Bittmann, R. M., \& Talyansky, R. (2018). Sentiment analysis in organizational work: Towards an ontology of people analytics. Expert Systems, 35 (5), 115. https://doi.org/10.1111/exsy.12289

12.Goyal, N. K. (2010). HRD climate survey of government aided senior secondary schools in Uttar Pradesh. International Transactions in Humanities and Social Sciences 2 (2), 261-275.

13.Gökalp, E., Demirörs, O., \& Eren, P. E. (2020). Public personnel management process capability assessment. Public Personnel Management, 49 (1), 111-140. https://doi.org/10.1177/0091026019833412

14.Grote, R. C. (2002). Performance Appraisal Question and Answer Book: A Survival Guide for Managers. New York: American Management Association.

15. Holloway, J. B. (2012). Leadership behavior and organizational climate: an empirical study in a nonprofit organization. Emerging Leadership Journeys, 5 (1), 29-35.

16.Yee, C. C., \& Chen, Y. Y. (2009). Performance appraisal system using multifactorial evaluation model. Proceedings of World Academy of Science: Engineering \& Technology, 41, 231-235. https://doi.org/10.5281/zenodo.1057055

17.Kets de Vries, M. F. R., Vrignaud, P., Korotov, K., Engellau, E., \& Florent-Treacy, E. (2006). The development of the Personality Audit: a psychodynamic multiple feedback assessment instrument. International Journal of Human Resource Managemen, 17 (5), 898-917. https://doi.org/10.1080/09585190600641040

18.Khan, N., \& Qureshi, M. I. (2020). A systematic literature review on online medical services in Malaysia. International Journal of Online and Biomedical Engineering, 16(6), 107-118. https://doi.org/10.3991/ijoe.v16i06.13573

19. Kundu, K. (2007). Development of the conceptual framework of organizational climate. Vidyasagar University Journal of Commerce, 12, 99-108.

20.Mathur, A., \& Nihalani, M. (2011). A study of organizational climate for the handicrafts industry of Jodhpur. SIES Journal of Management 7 (2), 37-45. 
21.Milutinovic, O., \& Kerkez, M. (2017). Mathematical model for the risk assessment in human resources function. Megatrend Review, 14 (3), 135-147.

22.Moyle, P., \& Hackston, J. (2018). Personality assessment for employee development: Ivory Tower or Real World? Journal of Personality Assessment, 100 (5), 507-517.

23.Nasreen, A., Varshney, P., \& Waseem, C. (2019). Organizational climate in NBFC: Implications on employee engagement. Amity Global HRM Review 9 (September), 7-14.

24.Neal, A., West, M. A., \& Patterson, M. G. (2005). Do organizational climate and competitive strategy moderate the relationship between human resource management and productivity? Research Article, 31 (4), 492-512. https://doi.org/10.1177/0149206304272188

25.Papsiene, P., \& Vaitkevicius, S. (2013). Network model of human resource evaluation and organizational climate interaction phenomenon. Inzinerine Ekonomika-Engineering Economics, 24 (3), 217-225. https://doi.org/10.5755/j01.ee.24.3.3897

26.Papsiene, P., \& Vaitkevicius, S. (2014). Human resource assessment impact to organization climate: case of Lithuanian public sector organizations. Inzinerine Ekonomika-Engineering Economics, 25 (2), 223-230. https://doi.org/10.5755/j01.ee.25.2.4701

27.Patterson, M., Warr, P., \& West, M. (2004). Organizational climate and company productivity: The role of the employee affect and employee level. Journal of Occupational and Organizational Psychology, (77), 193-216. https://doi.org/10.1348/096317904774202144

28.Protasova, L. A. (2010). Social and psychological compatibility of parties to an educational process. Психология, 5, 153-155.

29.Purohit, B., \& Wadhwa, A. (2012). Organisational climate from view point of motivation in district hospital, India. Health, 4 (7), 400-406. https://doi.org/10.4236/health.2012.47063

30.Rekasiute-Balsiene, R. (2005). Verslo organizaciju klimato ivertinimo galimybes. Psichologija, 31, 86-100. https://doi.org/10.15388/Psichol.2005. 4336

31.Schneider, B., \& Barbera, K. M. (2014). The Oxford Handbook of Organizational Climate and Culture. Oxford University Press.

32.Srivastav, A. K. (2009). Heterogeneity of organisational climate. Research and Practice in Human Resource Management, 17 (2), 1-13.

33.Stan, O. M. (2018). Steps towards sustainability - human resource capital and employee wellbeing - benchmarking evidence. Economics, Management \& Financial Markets, 13 (3), 290-300.

34.Tan, C. L., \& Nasurdin, A. M. (2011). Human Resource management practices and organizational innovation: Assessing the mediating role of knowledge management effectiveness. Electronic Journal of Knowledge Management, 9 (2), 155-167.

35.Thom, N. N., \& Ritz, A. (2004). Viesoji vadyba. Inovaciniai viesojo sektoriaus valdymo metmenys. Vilnius: Lietuvos teises universiteto leidybos centras.

36.Vrchota, J., \& Řehoř, P. (2019). The influence of a human resource strategy to the function of human resource processes in small and medium-sized enterprises (SMEs). Serbian Journal of Management, 14 (2), 299-314. https://doi.org/10.5937/sjm14-19588

37.Wang, L., Yuan, X., \& Elhoseny, M. (2019). Research on human resource performance and decisionmaking evaluation based on fuzzy mathematics and clustering model. Journal of Intelligent \& Fuzzy Systems, 37 (1), 171-184. https://doi.org/10.3233/JIFS-179075

38. Weer, C. H., \& Greenhaus, J. H. (2020). Managers' Assessments of Employees' Organizational Career Growth Opportunities: The Role of Extra-Role Performance, Work Engagement, and Perceived Organizational Commitment. Journal of Career Development,47 (3), 280-295. https://doi.org/10.1177/0894845317714892 